\title{
Procurement Maturity and IT-Alignment Models: Overview and a Case Study
}

\author{
X.C. Xing \\ J. Versendaal \\ J.M. van den Akker \\ B. de Bevere
}

Technical Report UU-CS-2011-018 August 2012

Department of Information and Computing Sciences Utrecht University, Utrecht, The Netherlands www.cs.uu.nl 
ISSN: 0924-3275

Department of Information and Computing Sciences Utrecht University P.O. Box 80.089 3508 TB Utrecht The Netherlands 


\title{
Procurement maturity and IT-alignment models: overview and a case study
}

\author{
Johan Versendaal • Marjan van den Akker • \\ Xiaochun Xing • Bastiaan de Bevere
}

Received: 3 October 2011 / Accepted: 15 March 2013 /Published online: 11 April 2013

(C) Institute of Information Management, University of St. Gallen 2013

\begin{abstract}
More and more firms urge their procurement departments to optimize their processes and leverage IT in order to reduce costs, increase quality and sustainability of received products and services, and shorten delivery times. Already in the nineties of the previous century Henderson and Venkatraman (IBM Systems Journal 32(1):4-16, 1993) identified business/IT-alignment as a key to organizational performance. Many maturity and IT-alignment models have since been developed, yet, specific procurement maturity models, including business/IT-alignment principles, are scarce. The aim of this paper is to provide an overview of procurement maturity models that include IT-alignment. We start with a presentation of business/IT-alignment principles, detailing dimensions (areas of concern) for alignment, specifically for the procurement domain. Subsequently, maturity principles are discussed, resulting in maturity levels for the procurement domain. Finally, an in depth study of a specialized procurement model for the construction industry is presented, in which simulation techniques for testing are successfully applied. The discussed models and application justify a business/IT-alignment approach for procurement departments.
\end{abstract}

Responsible Editor: Hans-Dieter Zimmermann

J. Versendaal $(\bowtie)$

HU University of Applied Sciences, Nijenoord 1,

3552 AS Utrecht, Netherlands

e-mail: johan.versendaal@hu.nl

M. van den Akker

Utrecht University, Utrecht, Netherlands

e-mail: j.m.vandenakker@uu.nl

\section{Xing}

Swets Information Services, Lisse, Netherlands

e-mail: xxing@nl.swets.com

B. de Bevere

Information Department at Ballast Nedam, Utrecht, Netherlands

e-mail: b.de.bevere@ballast-nedam.nl
Keywords Procurement · Purchasing · Maturity · Business/ IT-Alignment

JEL M15

\section{Introduction}

The usage of IT for the procurement business function of firms has increased since the late nineties of the previous century. Numerous benefits have been promised by consultancy firms and IT vendors, like reduced procurement costs, improved product and/or service quality, shortened delivery times, improved supplier relationships and more. Quite a number of cases show that at least part of the promises proved to be right (cf. Versendaal \& Brinkkemper 2003). Yet, leveraging IT for procurement to its full extent is a complex task. For example, when implementing e-procurement software, among other things, an organization needs to make projects, budget and management authorization responsibilities explicit. If such an organization is incapable of doing so, the e-procurement software cannot be optimally configured. Likewise problems have been identified as the 'productivity paradox' (Brynjolfsson 1993), and is among others addressed by Henderson and Venkatraman (1993) stating that with every ITimplementation, strategy and operations on the one hand ('strategic fit'), and business and IT on the other hand ('functional integration') need to be in synchronization with each other. Figure 1 shows Henderson and Venkaraman's so-called strategic alignment model.

Since 1993 scholars have performed research on strategic alignment (e.g. Luftman et al. 1999) and also practitioners, particularly Chief Information Officers (CIOs) still identify the matter as an important aspect and even concern of their daily work (e.g. Lawinski 2011). We follow both scholars and practitioners in labeling the matter as Business/IT-alignment. 


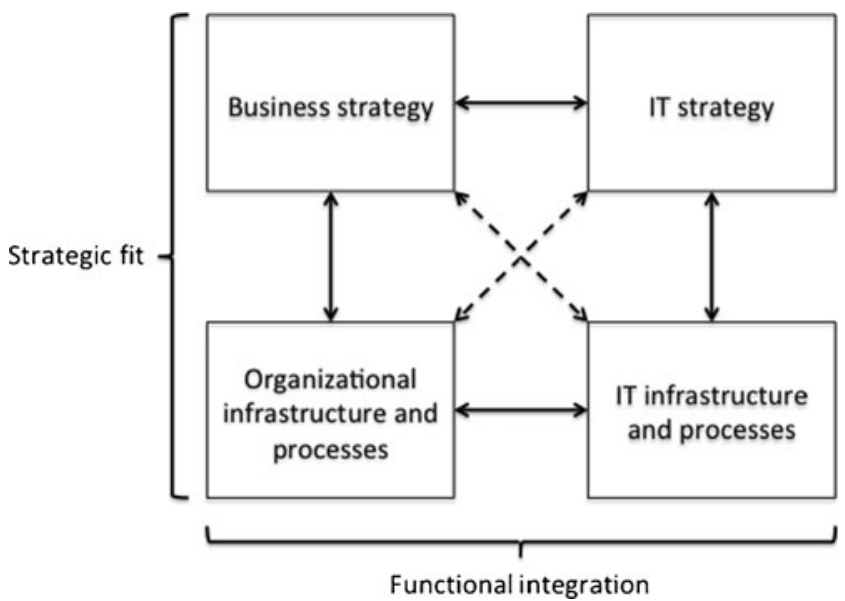

Fig. 1 Strategic alignment model (Henderson \& Venkatraman 1993)

Business/IT-alignment is associated with maturity: 'in synchronization' implies that each of the mentioned domains is equally developed (mature), and in synchronization with the other domains. Maturity comes with stages, and is often based on the Capability Maturity Model leveling (Paulk et al. 1993) as developed by the Software Engineering Institute (Becker et al. 2010).

There are not many existing particularly scientific models for procurement maturity and IT-alignment. A major contribution of this paper is to provide insight in and to position those procurement maturity models available that include IT-alignment. We further include a study of the construction and analysis of a particular procurement model for the construction industry. The paper is organized as follows. First generically and then for procurement specifically we elaborate on, and provide an overview of, the alignment of business and IT, maturity leveling, and the link between maturity and business/IT-alignment on the one hand and organizational performance on the other. We continue with the application of business/IT-alignment principles for procurement through a study for the construction industry. Finally we present our conclusions.

\section{Procurement maturity, alignment and performance}

Procurement alignment

Since Henderson and Venkatraman (1993), many authors have proposed further extensions and operationalisations of Henderson and Venkatraman's basic model. Maes et al. (2000), for example, split the IT dimension of Henderson and Venkatraman into two sub-dimensions: Information/Communication, and actual Technology (systems, databases, etc.). Also, the business domain has been divided into separate sub-dimensions. For example Turban et al. (1999) explicitly identified 'corporate culture' and 'employees and roles' as business sub-dimensions (Batenburg \& Versendaal 2004). Scheper (2002) proposed four generic business subdimensions and one IT dimension to be in synchronization with each other; listed:

- Organization and processes: an organization's structure and its business processes and workflow

- Monitoring and control: management processes in an organization

- Strategy and policy: an organization's strategy and protocols

- People and culture: human resources management in an organization

- IT: application of information technology in an organization

He researched the validity of these particular dimensions through an extensive application at housing corporations and healthcare institutes.

As for the procurement domain, being our business function of focus, numerous authors have identified success factors of implementation of IT-enhanced procurement (eprocurement), identifying e.g. management commitment and process re-engineering as pre-conditions. Croom and Brandon-Jones (2007) for example, discuss the impact and anticipated benefits of e-procurement for the rest of the organization, through process re-design, user compliance, compliance by suppliers (integration with the e-procurement software), and integration with existing legacy. These topics can also be projected onto Scheper's dimensions. Schiele (2007) combined earlier efforts in drilling down the procurement business domain in multiple dimensions, yet, without taking the IT dimension into account; he deduced the following procurement business dimensions

- Planning

- Structural organization

- Process organization

- Human resources

- Controlling

In 2006 Beukers et al. (2006) were the first to use business/IT-alignment principles explicitly by using business and IT dimensions that should be in synchronization. For a specific case in the insurance sector they successfully applied the same dimensions as Scheper, resulting in a business/IT-alignment based roadmap for professionalization of the procurement business function at the insurance company. Also in the healthcare industry, Plomp and Batenburg (2009) applied Scheper's dimensions in the procurement domain successfully. In 2006 and 2007, Berenschot, a major Dutch business consultancy firm confirmed that dimensioning along business and IT for 
synchronization is best practice: a survey among 285 organizations in the Netherlands showed that the organizations can be assessed as for each of the dimensions (Stalenhoef et al. 2007):

- Goal \& Strategy

- Process

- Control

- Organization

- Information

- Technology

Note that with minor differences, the dimensions can be recognized or deduced from Scheper. In 2008, Kroese et al. (2008) based their research on Berenschot's data and leveraged the same dimensions for guiding e-procurement implementation. Their research is the basis for a roadmap of specific e-procurement features to implement: if an eprocurement feature is expected to have another feature implemented (feature-synchronization), then both of them need to be implemented. Batenburg and Versendaal (2008) use the same business dimensioning as Kroese et al. (2008) and support the validity of the dimensions, as an approach for professionalizing the procurement function.

\section{Procurement maturity}

Maturity models are not uncommon in Information Systems (IS) research. Becker et al. (2010) provide an overview of maturity models in the IS-practice. They indicate that many of maturity levels in maturity models are based on the Capability Maturity Model (CMM), or the associated Software Process Maturity Framework (SPMF) and Capability Maturity Model Integration (CMMI) (Paulk et al. 1993). CMM maturity leveling was originally developed specifically for software development, but showed its usefulness for organizational maturity in general (Becker et al. 2010; Mettler and Rohner 2009). Maturity models that base their leveling on CMM have maturity levels in accordance with the following CMM-levels:

- Initial

- Repeatable

- Defined

- Managed

- Optimised

For example, for Business Process Management (Systems) maturity, Rosemann and de Bruin (2005) and Raschke and Ingraham (2010) base their research one-toone on the CMM leveling. In the context of particular business functions one can identify deviations from the CMM model. E.g. in the domain of Marketing \& Sales, Batenburg and Versendaal (2004) define increased maturity as moving from product-orientation towards customer orientation (indicating four levels). Another maturity level perspective comes from the general principle of enlarging your scope (taking a broader perspective) when increasing maturity. For a Product Lifecycle Management maturity model as constructed by Batenburg et al. (2006) there are only 4 maturity levels, inheriting the principle of taking a broader scope/perspective:

- Initial / Ad-hoc

- Department-oriented

- Organization-oriented

- Inter-organizational.

Likewise, in the domain of Logistics and Warehousing van de Wijngaert et al. (2008) defined the levels:

- Pre-supply chain

- Functional orientation

- Internal integrated

- External integrated

- Value chain integrated.

Finally, in the procurement domain, van Weele et al. (2000) combined existing procurement maturity stages identification from scholars in the $80 \mathrm{~s}$ and $90 \mathrm{~s}$ of the previous century into a comprehensive set of procurement maturity levels that increase through enlarged scope/perspective (see also Rozemeijer 2000). They identify the levels:

- Transaction orientation

- Commercial orientation

- Coordinated purchasing

- Internal integration

- External integration

- Value chain orientation

Subsequent procurement maturity models base their levels on van Weele et al. (2000). Beukers et al. (2006) use the same six levels for application in the banking \& insurance sector; the same holds for Plomp and Batenburg (2009), but then for the healthcare industry. Batenburg and Versendaal (2008) use the first four levels from van Weele, and add a fifth level by combining the fifth and sixth level from van Weele et al. (2000). Berenschot, in their survey (Stalenhoef et al. 2007), also use these five levels. All mentioned scholars and practitioners apply the levels to indicate opportunities of growth and professionalization as for the procurement department: 'going for the next level'.

Procurement maturity and performance

The cause for the search for business/IT-alignment is fed by the suggested link to (organizational) performance, and the underlying hypothesis that improvement of business/IT-alignment \& maturity would lead to increased (organizational) performance. Indeed, various quantitative studies support this 
hypothesis. For example, a quantitative study on Business Process Management maturity in relation to Process Performance, from Capgemini in cooperation with Utrecht University (Loggen et al. 2011), indicates significant relationship under regression $\left(N=138 ; \mathrm{R}^{2}=.422\right)$. Also for procurement several practical studies show that higher procurement maturity tends to increase procurement and/or organizational performance (Schiele 2007, Raschke \& Ingraham 2010, Plomp \& Batenburg 2009, Batenburg \& Versendaal 2008). Only the latter two include IT specifically as one of the maturity dimensions.

The measurement of procurement performance is also an important part of the studies on procurement performance in relation to procurement maturity. Most common is the identification of (procurement) operational performance indicators like costs for acquiring, quality (of purchased goods/services), and delivery time; e.g. Batenburg and Versendaal (2008) and Plomp and Batenburg (2009) use these type of indicators. Others take financial indicators and include a supply chain wide benefits perspective, e.g. as argued by Pollice and Fleury (2011). In our current age of partnering for smart innovations, and increased effectiveness of communication means this is becoming a more and more logical perspective.

Introduction to the in-depth study

Having provided an overview of maturity models, including the IT-alignment perspective, and also having focused on the procurement business function in organizations, we now perform an in-depth study for procurement maturity modeling and IT-alignment to investigate:

1) whether for a particular industry (in this case the construction industry) one can inherit the 'common' dimensions as identified by Scheper (2002) and other scholars;

2) whether for the construction industry comparable maturity leveling can be used;

3) whether the maturity/alignment link with performance holds for a particular organization in the construction industry.

We chose the construction industry as our domain of study, as it is an industry in which in general procurement maturity is considered low (e.g. van Weele 2005): we claim to have much potential for practical 'relevance' (Hevner et al. 2004). Describing the case study we explicitly address its validity aspects by following Yin (2003, p.34). Yin identified four types of validity tests for case study research, with associated tactics:

- construct validity: use multiple sources of evidence; establish chain of evidence; have key informants review draft case study report
- internal validity: do pattern-matching; do explanationbuilding; address rival explanations; use logic models

- external validity: use theory in single-case studies; use replication logic in multiple-case studies

- reliability: use case study protocol; develop case study database

In the following we mention adherence to these types of validity and possible threats.

\section{An in-depth study of a procurement maturity modeling for the construction industry}

Characteristics of the construction industry

The construction industry has particular characteristics as can be found in literature; Table 1 lists the details.

Also, the construction industry is subject to many challenges. The drivers of change and their implications for the Construction industry are summarized in the first two columns of Table 2.

Table 1 Construction industry characteristics

\begin{tabular}{|c|c|}
\hline Characteristic & Definition \\
\hline Project-oriented processes & $\begin{array}{l}\text { Core business processes, such as } \\
\text { design, production and } \\
\text { procurement processes are } \\
\text { organized around projects rather } \\
\text { than functional departments } \\
\text { (Gann \& Salter 1998, Gann \& } \\
\text { Salter 2000, Hobday 2000). }\end{array}$ \\
\hline One-off products & $\begin{array}{l}\text { Products that are produced as a } \\
\text { result of the specific scenarios } \\
\text { and conditions of a certain } \\
\text { project. (Bresnen et al. 2004). }\end{array}$ \\
\hline Decentralized project teams & $\begin{array}{l}\text { Project teams are not centrally } \\
\text { dispatched creating considerable } \\
\text { horizontal and vertical } \\
\text { distinction within individual } \\
\text { construction companies and a } \\
\text { high level of separation between } \\
\text { project activities and broader } \\
\text { corporate strategies (Bresnen \& } \\
\text { Marshall 2000, Dubois \& Gadde } \\
\text { 2002). }\end{array}$ \\
\hline $\begin{array}{l}\text { Cross-functional and inter- } \\
\text { organizational contractual } \\
\text { and working relationships }\end{array}$ & $\begin{array}{l}\text { The relationship is built with } \\
\text { coordination and cooperation of } \\
\text { specialists of different professional } \\
\text { background who take responsibility } \\
\text { of different parts of a project and } \\
\text { follow diverse institutional norms } \\
\text { defined within an organization or } \\
\text { by another party of the supply } \\
\text { chain (Dubois \& Gadde 2002, } \\
\text { Bresnen et al. 2004). }\end{array}$ \\
\hline
\end{tabular}


Table 2 Drivers of change in the construction industry and their relation to the maturity model dimensions

\begin{tabular}{|c|c|c|}
\hline Drivers of change & Implications in the construction industry & Related dimension in the model \\
\hline $\begin{array}{l}\text { Vertical consolidation } \\
\text { (Thiry \& Deguire 2007) }\end{array}$ & Aligns the project goal and process with the organizational ones & Goal, Process, Organization \\
\hline Culture (Yitmen 2007) & $\begin{array}{l}\text { Affects organizational structure, project process and control to } \\
\text { improve performance on both daily and long-term manner }\end{array}$ & Organization, Process, Control \\
\hline $\begin{array}{l}\text { Adoption of ICT } \\
\text { (Rankin \& Luther 2006) }\end{array}$ & $\begin{array}{l}\text { Facilitates exchange of information from a process and organizational } \\
\text { practices point of view }\end{array}$ & Information, E-technology \\
\hline $\begin{array}{l}\text { Control of project } \\
\text { (Gann \& Salter 2000) }\end{array}$ & Improves the control over time, budget and quality of construction projects & Control \\
\hline IT usage (Yitmen 2007) & $\begin{array}{l}\text { Enhances coordination between project participants, enables cost } \\
\text { saving and streamlines operational processes }\end{array}$ & Control, Process, E-technology \\
\hline $\begin{array}{l}\text { E-procurement } \\
\text { (Eadie et al. 2010) }\end{array}$ & Offers opportunities for the purchasing function and the procurement process & $\begin{array}{l}\text { E-technology, Information, } \\
\text { Process }\end{array}$ \\
\hline
\end{tabular}

Formation of the model for the construction industry

We choose to take the generic and validated procurement framework of Batenburg and Versendaal (2008) as a starting point for our objective to create a Construction Industry specific maturity matrix to determine an operational procurement maturity strategy for this industry (see Fig. 2); this creates a grounding for external validity as well. We are confirmed in our choice as we can easily map the drivers of change identified in the previous paragraph onto all of the rows of the framework of Batenburg and Versendaal. The third column of Table 2 shows this mapping. Considering reliability, in constructing the model operationalisation we take a three-phase approach:

- Phase 1: Construct a draft maturity matrix based on Batenburg \& Versendaal's model, taking into account related literature, construction industry characteristics and drivers of change (Tables 1 and 2).

- Phase 2: Improve this maturity matrix through explorative interviews. Because of the lack in refining the dimensions of the maturity matrix on the operational level from literature study, we use the semi-structured interviews as means of probes (Hutchinson \& SkodolWilson 1992). The significance of probing (Barriball \& While 1994) is applied to the full extent during the 3 explorative interviews.

- Phase 3: Complete the remaining gaps in the maturity matrix through specific literature

In phase 1, we integrate construction industry characteristics and drivers of change in the construction industry with Batenburg \& Versendaal's (2008) model (see Fig. 2).

Particularly, we take the existing operationalisation of the model of Batenburg and Versendaal (2008) with additional literature and practices (specifically Stalenhoef et al. 2007, Capgemini Consulting 2008, Schiele 2007, Cheng et al. 2010, Versendaal \& Brinkkemper 2003) and with the characteristics (Table 1) and drivers of change (Table 2) in order to define measurable indicators of the independent part of our maturity model. Taking these multiple perspectives we intend to manage construct validity. Table 3 shows part of the indicators for the Process and E-Technology dimensions of the maturity model.

Subsequently we define draft characteristics per level for each of the measurable indicators, using Batenburg and

Fig. 2 Maturity model outline

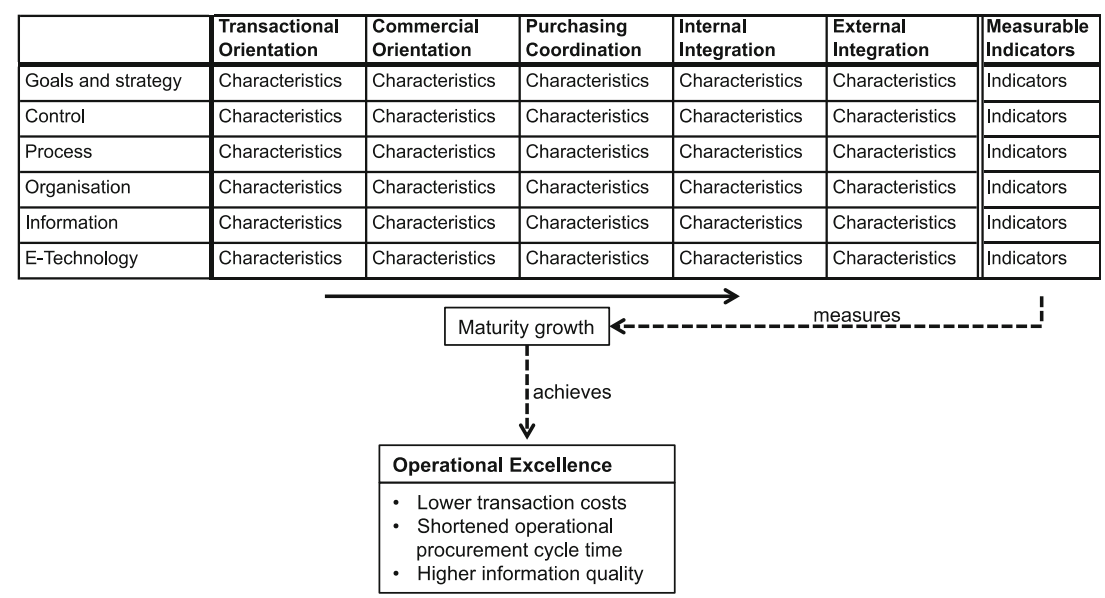


Table 3 Defined measurable indicators

\begin{tabular}{ll}
\hline Dimension & Measurable indicator \\
\hline Process & Ordering process \\
& Receiving process \\
& Payment process \\
E-technology & Degree of system integration \\
& Sophistication of data process \\
& and network technology
\end{tabular}

Versendaal (2008) and the other above mentioned sources. This results in a draft maturity matrix. E.g., find below the characteristics per level that we identify for the measurable indicator Ordering process:

Ordering process

- Transactional: To fulfill the ad-hoc demand for materials or subcontracting.

- Commercial: As previous, and concerns about the comparison on the price.

- Purchasing coordination: As previous, and facilitated by systems for registration and contract compliance.

- Internal: As previous, and integrated with planning system to form an organization-wide P2P standard process.

- External: As previous, and extends the planning with suppliers through network enabled systems.

As optimizing operational procurement is much related to efficiency, we decide to define performance through operational excellence measurements (Treacy \& Wiersema 1996). Operational excellence aims at 'best total cost' by operating in an optimized supply chain, with standardized operation and central control, and completing transactions quickly, reliably and in an integrated manner. From the original model of Batenburg and Versendaal (2008) we adopt the time, cost and quality performance indicators. These are made specific for the Construction industry taking an operational excellence perspective: procurement cycle time (e.g. Minahan \& Degan 2001), transaction costs (e.g. Clemens et al. 1993), and information quality (e.g. Monczka et al. 1998). We consider the described choices as contributing to construct validity.

In phase 2 of the operationalisation, again following construct validity tactics, through explorative interviews, the model was further drafted. Three respondents from three different construction firms with a procurement expert profile participated. The explorative interviews were designed in the semi-structured form. The selected respondents were all familiar with the context and each interview takes about $1 \mathrm{~h}$ and 15 min (Griffee 2005). The respondents were from organizations either operating internationally or as a major player in the Netherlands in the construction industry. They were fully aware of the intention of the explorative interviews and got familiar with the questions beforehand (the questionnairebook is available on request by mailing the first author). All interviews are recorded with a note book and a pen as the first two respondents feel more comfortable without a tape record. It was possible to write down almost everything while the respondents were talking. And the plotted process flow chart at the beginning of the interview is making all the following discussions to the point. The recorded answer of each question is briefly restated before the interview moves on to the next one in order to avoid reinterpretation (Leech 2002).

The interview notes are reviewed by following Miles \& Huberman's (1994) steps of data analysis. Following these steps add to the reliability of the research.

The interviews were individually conducted by following the process improvement approach (as exemplified by Brinkkemper et al. 2008) which suggests that the desired change in maturity require one or more changes in the process. Thus the process dimension was assessed first (checking the maturity characteristics of each of the process-related measurable indicators) and used to define and further detail the existing maturity level. The exploration was subsequently carried out vertically in the matrix of Fig. 1, revealing detailed characteristics for the other measurable indicators. The vertical approach in fact applies the business/IT-alignment principle: for a certain dimension (in this case the process dimension), the other dimensions can be determined, suggesting synchronization between dimensions. The horizontal exploration followed by examining the evolvements from history and looking forward to future improvements. For example, when the procurement process maturity level of a respondent's construction firm was determined purchasing co-ordination, subsequently commercial orientation (historical exploration) and internal integration (future improvements exploration) processes were defined. The final result was a detailed maturity matrix.

Find below (Fig. 3) the resulting process description for the Construction industry on purchasing coordination level (red font in the middle cell on the top bar). The processrelated measurable indicators ordering process, receiving process and payment process are depicted as major boxes. Orange colored activities are semi-automated.

In the third phase additional literature was sought in order to fill in the remaining gaps in the maturity model's operationalisation. Due to space limitations we will not elaborate on this, but details are available on request.

Note that the change of process of which we assess the effect in terms of maturity also is a step to improve business/IT-alignment, since it includes automation of a number of steps in the process.

Model validation

The model and the maturity-performance link identified in this paper have been validated by a case study at Ballast 
Transaction | Commercial | Coordination | Internal | External

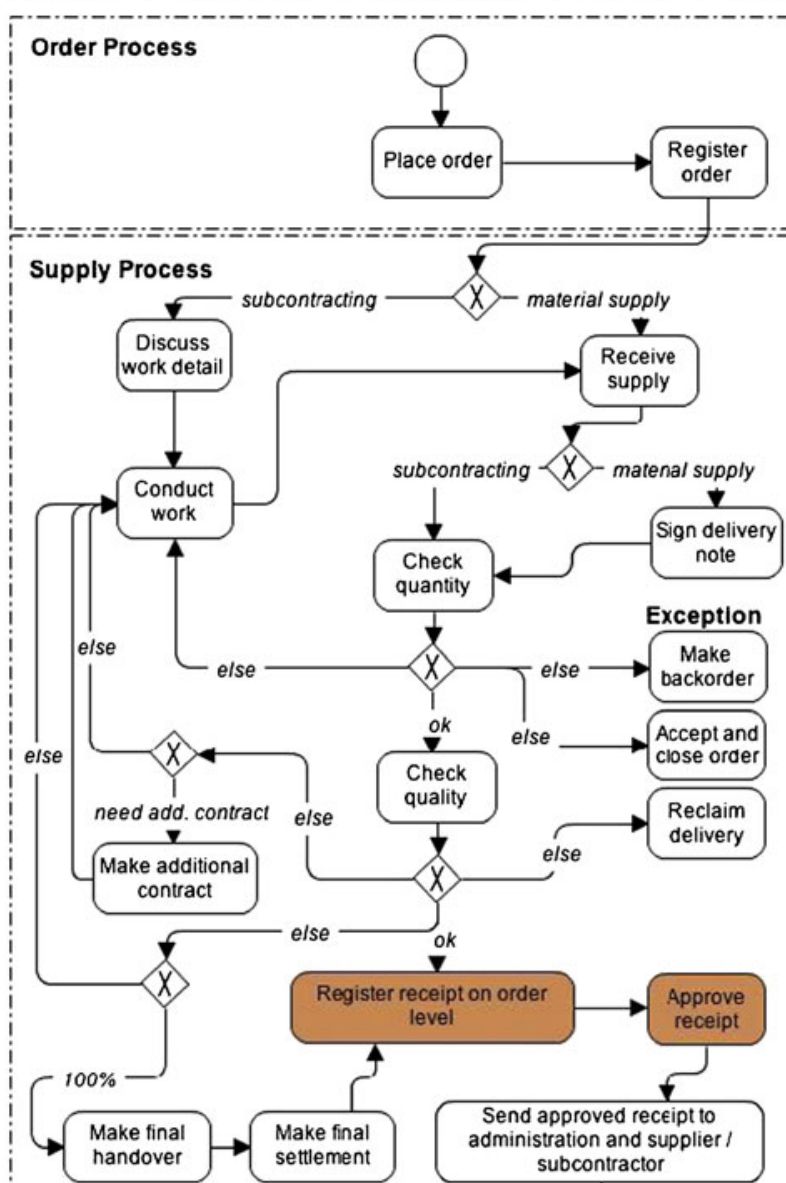

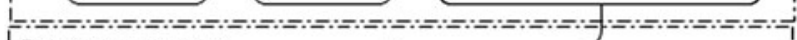

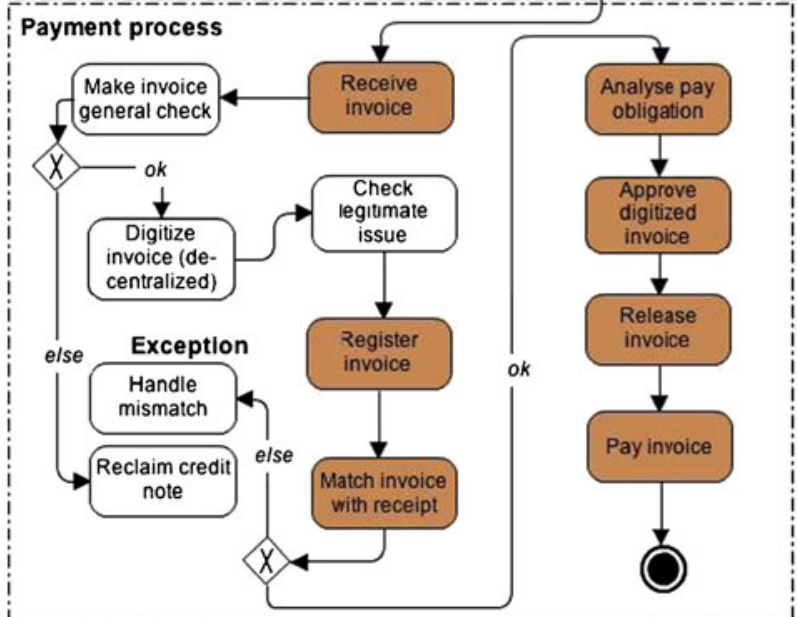

Fig. 3 Characterization of the process dimension on purchasing coordination maturity level

Nedam (a major Dutch construction firm) which includes a discrete-event simulation.

To analyze the operational procurement processes using the maturity model a series of workshops have been carried out at Ballast Nedam with representatives of different functions in the operational procurement process. As a result,
Ballast Nedam is evaluated to be on level 3 of the maturity matrix with diversity of process details and e-procurement adoptions in divisions and subsidiaries.

Simulation is a widely used operations research and management science technique. Through simulation, researchers can evaluate both the quantitative (performance) properties of a system with analytical or numerical modeling and qualitative (behavioral) properties with structural or process modeling (Pooley 2007). In discrete-event simulation, a system is modeled by a state (representing the situation at a fixed moment in time), which will be changed at specific moments in time by the occurrence of events. A common modeling paradigm in discrete-event simulation is to describe the system as a network of servers and queues. This paradigm is perfectly suited to model the work flow of the procurement process of a particular firm from the Construction industry. Ballast Nedam, a major Dutch construction firm, provided the data for our simulation; they recently changed the procurement function within the company, and therefore can easily provide more longitudinal data as simulation information. A discrete-event simulation model usually includes entities that are subject to uncertainty and hence modeled by stochastic variables. In our case, this includes arrival times of deliveries, processing times, and availability of certain services required in the process.

To measure the relation between maturity growth and the operational procurement performance with respect to operational excellence, we evaluate the three performance measures for operational excellence that we have identified in the previous section: transaction cost, procurement cycle time and information quality. The current maturity of the procurement process at Ballast Nedam is assessed as third level, purchasing coordination, during the year 2009, which is defined as scenario S09. This is compared to the process in 2002, denoted by scenario S02, which assessed at second level, commercial orientation. The scope of the simulation is the part of the operational procurement process which starts from "register receipt" and ends with "ready for pay". This part of the process does not include the lead time which is determined by the process and policy of the supplier. The simulation model of the Ballast Nedam configuration of Fig. 3 is depicted in Fig. 4; during the workshops this basic outline of the process proved to be identical for both scenarios (S02 and S09). There are three states of the products that are flowing in the process namely: receipt (1), invoice matched (with receipt) (2), (invoice) mismatch (with receipt) (3). The major change between $\mathrm{S} 02$ and S09 is in S09, e-technology has been implemented, including an electronic procurement system for work-planning and execution, and an extension of the ERP-system with a combination of e-informing (see de Boer et al. 2002). 


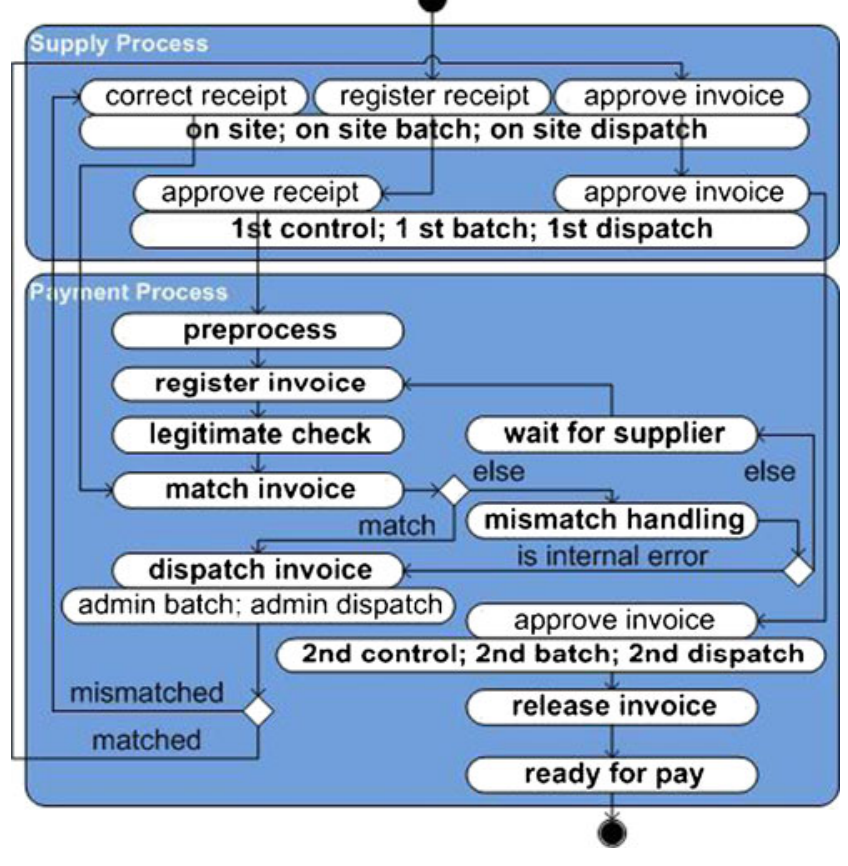

Fig. 4 Ballast Nedam's modeled procure-to-pay (P2P) process

The performance measures transaction cost, procurement cycle time and information quality are included in our simulation model as follows:

- The average workload of the servers, in terms of the number of products being processed, is used as bases to calculate the personnel salary and the postal costs.

- The cycle time per receipt.

The information quality is measured by the waiting time in the queues in the simulation. The waiting time represents the period during which information about the transactions is only available locally with limited accessibility and traceability. The shorter the waiting time, the better the information of the transactions is shared, communicated and controlled.

In order to address reliability and construct validity of the simulation model, we follow the seven-step approach defined by Law (2009). For reasons of brevity, we will not describe all steps here. An important step is to write an "Assumptions Document", which has been agreed upon with the principal providing the input for the simulation.

In our experiment we performed 20 simulation runs designed for both scenarios. The 20 runs in the experiment are separate runs, each of which starts with a warm-up period to get rid of initialization effects, followed by one observation period. Using the method of separate runs, the observation periods are independent. The observation period length is 1 year for each run with the warm up time to be $180 \mathrm{~h}$.

The columns in Fig. 5 show the average workload of each server during the simulation.
The ' 0.43 ' in the column 'workload' for on-site registration' indicates that the average amount of products which is either a receipt (state 1 ) or invoice (state 2 or 3 ) being processed by each available server (person) is 0.43 per hour. If there is a service capacity of 18 , the process is modeled in the simulation by 18 parallel servers and it follows that the total processing power required is 18 times 0.43 which equals 7.74. This is represented in the columns 'amount' and 'total'. The performance of the underlined dispatch related servers and the "wait for supplier" server however are calculated differently. The dispatch related servers need a large processing time (around $8 \mathrm{~h}$ ), but during this time they can process all receipts that were available for processing at the same time. The 'wait for supplier' is purely an artificial delay and will be omitted from the further calculation.

The numbers written non-bold imply an overall decrease of required processing capacity in S09 compared to S02; numbers in bold (4 functions) indicate an increase. From the exceptional 4 functions, the on-site registration and legitimate check require more processing in $\mathrm{S} 09$ than in S02. This longer processing time is due to more receipt registration details and stricter EU working regulations for these two functions respectively. The absolute differences in 1st control and 2nd control are not considered to be significant. Except for the "wait for supplier" and dispatching functions, the functions are analyzed in two groups. Observe that the dispatching functions have a very strong time reduction from S02 to S09. One group is indicated in the green box (rows 3 to 8 ) in Fig. 5 and outlines the decentralized (on-site related) part of the construction team. The total processing power of S09 is 15.12 and 10.44 for S02. The functions in the other groups are performed at central administration based and show a decrease from 10.73 in S02 to only 1.77 in S09. Summarizing, our simulation suggest a strong efficiency increase which may result in a large reduction of administration personnel.

In the simulation we also measured the cycle time. The histogram for S09 is shown on the left side of Fig. 6 and the one for $\mathrm{S} 02$ is on the right side. The average cycle time of 210622 simulated transactions in 20 runs of S02 is 231.95 (hour, see the horizontal axis). The 249502 transactions in S09 find their cycle time is fluctuating around 98.41 (hour). The majority of transactions $(79.89-28.05 \%=61.84 \%)$ in S02 have a completion time between 28 calendar days (120 working hours) and 49 calendar days (280 working hours), while almost $81.97 \%$ transactions in S09 are done within 28 calendar days (120 working hours). The improvement in cycle time reduction is obvious and proportional to the maturity grow.

Recall that the information quality is measured by the waiting time in the queues in the simulation.

Figure 7 illustrates the information waiting time of $\mathrm{S} 02$ and S09. Waiting time is decreasing in almost all the 
Fig. 5 Simulation procure-topay process

\begin{tabular}{|c|c|c|c|c|c|c|}
\hline & & S02 & & & S09 & \\
\hline & workload & amount & total & workload & amount & total \\
\hline on-site registration & 0.43 & 18 & 7.74 & 0.68 & 18 & 12.24 \\
\hline on-site batch & 0 & 1 & 0 & 0 & 1 & 0 \\
\hline on-site dispatch & 114.74 & & & 0.02 & & \\
\hline 1st control & 0.15 & 18 & 2.7 & 0.16 & 18 & 2.88 \\
\hline 1st batch & 0 & 1 & 0 & 0 & 1 & 0 \\
\hline 1 st dispatch & 94.9 & & & 0.02 & & \\
\hline 2nd control & 0.05 & 1 & 0.05 & 0.06 & 1 & 0.06 \\
\hline 2nd batch & 0 & 1 & 0 & 0 & 1 & 0 \\
\hline 2nd dispatch & 0.49 & & & 0.01 & & \\
\hline preprocess & 0.3 & 2 & 0.6 & 0.22 & 1 & 0.22 \\
\hline register invoice & 1.1 & 5 & 5.5 & 0.25 & 2 & 0.5 \\
\hline legitimate check & 0.11 & 1 & 0.11 & 0.42 & 1 & 0.42 \\
\hline match invoice & 1.05 & 4 & 4.2 & 0.27 & 2 & 0.54 \\
\hline mismatch handling & 0.25 & 1 & 0.25 & 0.02 & 1 & 0.02 \\
\hline wait for supplier & $43.1^{-}$ & & & $4 \overline{8} . \overline{4} 5^{---}$ & & \\
\hline admin batch & 0 & & 0 & 0 & $\overline{1}$ & 0 \\
\hline admin dispatch & 67.74 & & & 0.01 & & \\
\hline release invoice & 0.02 & 1 & 0.02 & 0.01 & 1 & 0.01 \\
\hline
\end{tabular}

processing steps and in S09 we especially observe minimal delays before the central administration. The legitimate check queue however becomes a bottleneck because of more required receipt registration details and stricter EU working regulations, as also mentioned earlier. Moreover, the waiting time is slightly longer in " 2 nd patch Q" and "pre-process Q". The sum of the waiting times in $\mathrm{S} 02$ is 120.4 (hour) and 56.74 (hour) in S09 which is less than half of that in S02. This again brings the conclusion that the information quality with respect to the timeliness has improved along with the maturity growth.

From the above, all three selected performance indicators of operational excellence are positively aligned with the maturity growth. With the maturity grow from level 2 to level 3 , the transaction cost is lower, the transaction cycle time is shorter and the information quality is higher.
Analysis of the study

Analyzing our study we summaries that the chosen dimensions (vertical axis of Fig. 2) were comfortably applied: not only could the drivers of change in the Construction industry (see Table 2 ) be easily projected onto the chosen dimensions, but also the explorative interviews at the case study organization provided values for the measurable indicators for the process and other dimensions. As for the horizontal axis of Fig. 2, the maturity levels of commercial orientation and purchasing coordination were easily recognized by the case study organization. Although the above confirms construct validity, threats to construct validity among others appear on the scope of the simulation. The following limitations and weaknesses are identified: 1) only three experts from three different construction firms have 
Fig. 6 Procurement cycle time measurement (horizontal: cycle time; vertical: frequency; reddotted line: cumulative value)

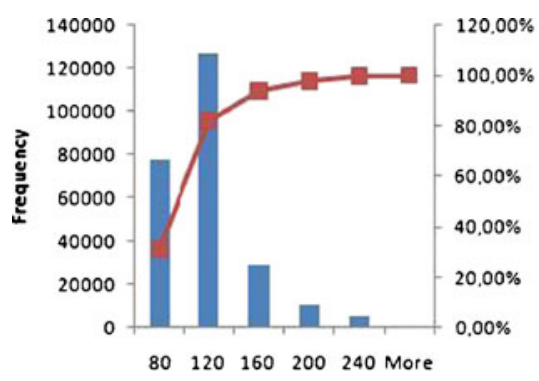

participated in the expert interviews; 2) the simulation's scope was on the receipt and payment processes (not including the ordering process, nor specifically including the other dimensions and measurable indicators, like E-Technologysystem integration); 3) the simulation's scope was related to the commercial level and purchasing coordination level, not addressing the other maturity levels.

As for the maturity/alignment and performance link, through simulation, the results show support for this assumption (internal validity), implying that a worthwhile consideration - when intending to improve the procurement business function - is to leverage the procurement maturity framework for the construction industry. We note however that the limited scope of the simulation is a threat to internal validity.

The simulated second and third maturity levels are instantiations of using logic models, which is itself a tactic of internal validity (Yin, 2003). This relation implicitly also sustain - in terms of construct validity-the correctness and completeness of the chosen dimensions and maturity levels (at least maturity level 2 and 3). The case study was designed as a specific instance for the construction industry from the generic procurement maturity model of Batenburg and Versendaal (2008) and Stalenhoef et al. (2007), which have been tested quantitatively. This contributes to external validity as for the other 1) (not simulated) maturity leveling, 2) procurement dimensions (like e-technology) 3) firms in the construction industry. Though still a number of limitations (threats to external validity) should be mentioned:

- only three procurement experts were involved in the interview sessions

- only the procurement dimension process (and to some extent e-technology) were simulated

- only the maturity levels commercial orientation and purchasing coordination were explicitly validated in the simulation;

- the procurement experts being interviewed came from organizations that were either on commercial orientation level, or purchasing coordination level

Summarizing, our study can be extended by simulating more level-transitions of the maturity model. Moreover, the measurable indicators of the maturity model were not all explicitly simulated, and are also not exhaustive: its completeness deserves further validation and review. The simulation scope can be extended to the full cycle of the 'procure-to-pay'-process.

\section{Conclusions}

Business/IT-alignment and maturity have been researched for some time. As for the procurement business function some models have been developed that indicate that increased

\begin{tabular}{|r|r|r|} 
& \multicolumn{1}{|c|}{ S02 } & S09 \\
\hline on-site Q & 0.3 & 0 \\
\hline on-site batch Q & 18.94 & 15.89 \\
\hline on-site dispatch Q & 8.09 & 0 \\
\hline 1st control Q & 0.17 & 0.14 \\
\hline 1st batch Q & 19.43 & 15.42 \\
\hline 1st dispatch Q & 7.97 & 0 \\
\hline 2nd control Q & 1.24 & 1.14 \\
\hline 2nd batch Q & 8.81 & 8.94 \\
\hline 2nd dispatch Q & 0.08 & 0 \\
\hline preprocess Q & 3.24 & 4.19 \\
\hline regi. invoice Q & 1.05 & 0 \\
\hline legi. check Q & 0 & 10.82 \\
\hline match invoice Q & 0.67 & 0.02 \\
\hline r/i match Q & 19.99 & 0 \\
\hline mismatch Q & 1.12 & 0 \\
\hline external Q & 0 & 0 \\
\hline internal Q & 18.95 & 0 \\
\hline admi. dispatch Q & 8.06 & 0 \\
\hline release Q & 2.29 & 0.18 \\
\hline ready for pay Q & 0 & 0 \\
\hline
\end{tabular}

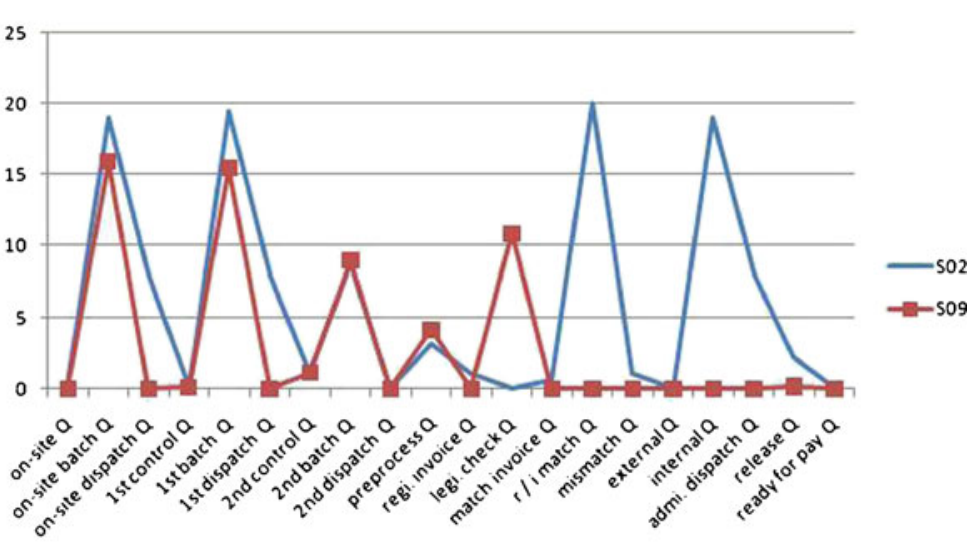

Fig. 7 Simulation procure-to-pay process 
maturity/alignment is related to increased (procurement) performance. This paper provided an overview of procurement maturity and IT-alignment models and operationalised a procurement maturity model for the construction industry. Contributing to the goals of the in-depth study as identified in the "Introduction to the in-depth study"-sub-section it showed that existing dimensions and maturity levels of procurement maturity and IT-alignment models provide a profound fundament for creating an industry specific maturity model (in this case for the construction industry). This particular maturity/alignment model can be used to assess the level of maturity of a construction firm's procurement function, and can be used as a strategy to define the next level. The correlation between the maturity growth and the performance achievement in terms of operational excellence is supported through simulation validation.

The usefulness of simulation tooling is confirmed in this research. Yet, demarcations, simplifications, assumptions and abstractions need to be made during simulation configuration, and therefore are prone to differences from the real world.

\section{References}

Barriball, K. L., \& While, A. (1994). Collecting data using a semistructured interview: a discussion paper. Journal of Advanced Nursing, 19, 328-335.

Batenburg, R., Helms, R., \& Versendaal, J. (2006). PLM roadmap: stepwise PLM implementation based on the concepts of maturity and alignment. International Journal of Product Lifecycle Management, 1(4), 333-351.

Batenburg, R., \& Versendaal, J. (2004). Business alignment in the CRM domain: Predicting CRM performance. Paper presented at the 12th European conference on information systems. Turku, Finland.

Batenburg, R., \& Versendaal, J. (2008). Maturity matters: Performance determinants of the procurement business function. Paper presented at the 16th European conference on information systems. Galway, Ireland.

Becker, J., Niehaves, B., Pöppelbuß, J. \& Simons, A. (2010). Maturity models in IS research. Paper presented at the 18th European conference on information systems, Pretoria, South Africa.

Beukers, M., Versendaal, J., Batenburg, R., \& Brinkkemper, S. (2006). The procurement alignment framework: construction and application. Wirtschaftsinformatik, 48(5), 323-330.

Bresnen, M., Goussevskaia, A., \& Swan, J. (2004). Embedding new management knowledge in project-based organizations. Organization Studies, 25(9), 1535-1555.

Bresnen, M., \& Marshall, N. (2000). Partnering in construction: a critical review of issues, problems and dilemmas. Construction Management and Economics, 18(2), 229-237.

Brinkkemper, S., Saeki, M., van de Weerd, I., \& Versendaal, J. (2008). Process improvement in requirements management: a method engineering approach. Lecture Notes in Computer Science, $5052,6-22$.

Brynjolfsson, E. (1993). The productivity paradox of information technology. Communications of the ACM, 36(12), 67-77.
Consulting, C. (2008). Supplier relationship management solutions: SRM research 2008-2009 solution analyses and business insights. Utrecht: Capgemini.

Cheng, J. C. P., Law, K. H., Bjornsson, H., Jones, A., \& Sriram, R. (2010). A service oriented framework for construction supply chain integration. Automation in Construction, 19(2), 245-260.

Clemens, E. K., Reddi, S. P., \& Row, M. C. (1993). The impact of information technology on the organization of economic activity: the 'move to the middle' hypothesis. Journal of Management Information Systems, 10(2), 9-35.

Croom, S., \& Brandon-Jones, A. (2007). Impact of e-procurement: experiences from implementation in the UK public sector. Journal of Purchasing \& Supply Management, 13, 294-303.

De Boer, L., Harink, J., \& Heijboer, G. (2002). A conceptual model for assessing the impact of electronic procurement. European Journal of Purchasing and Supply Management, 8(1), 25-33.

Dubois, A., \& Gadde, L.-E. (2002). The construction industry as a loosely coupled system - implications for productivity and innovatively. Construction Management and Economics, 20(7), 621631.

Eadie, R., Perera, S., \& Heaney, G. (2010). Identification of eprocurement drivers and barriers for UK construction organizations and ranking of these from the perspective of quantity surveyors. Journal of Information Technology in Construction, 15.

Gann, D. M., \& Salter, A. J. (1998). Learning and innovation management in project-based, service-enhanced firms. International Journal of Innovation Management, 2(4), 431-454.

Gann, D. M., \& Salter, A. J. (2000). Innovation in project-based, service-enhanced firms: the construction of complex products and systems. Research Policy, 29(7-8), 955-972.

Griffee, D. T. (2005). Research tips: interview data collection. Journal of Developmental Education, 28(3), 36-37.

Henderson, J. C., \& Venkatraman, N. (1993). Strategic alignment: leveraging information technology for transforming organizations. IBM Systems Journal, 32(1), 4-16.

Hevner, A. R., March, S. T., Park, J., \& Ram, S. (2004). Design science in information systems research. MIS Quarterly, 28(1), 75-105.

Hobday, M. (2000). The project-based organization: an ideal form for managing complex products and systems? Research Policy, 29(78), 871-893.

Hutchinson, S., \& Skodol-Wilson, H. (1992). Validity threats in scheduled semi structured research interviews. Nursing Research, 41(2), 117-119.

Kroese, E., Teuling, J. den., Versendaal, J., Batenburg, R. \& KampSlootweg, H. van de (2008). Aligning procurement: An eprocurement mapping and deployment model. Paper presented at the 17th Annual conference of the international purchasing \& supply education and research association, Perth, Australia.

Law, A. M. (2009). How to build valid and credible simulation models. Paper presented at the 37th Conference on winter simulation, Austin, USA.

Lawinski, J. (2011). Business, IT alignment a top priority for CIOs. CIO insight newsletter. retrieved 2012-09-10, from http:// www.cioinsight.com/c/a/IT-Management/Business-IT-Alignmenta-Top-Priority-for-CIOs-547064/.

Leech, L. B. (2002). Techniques for semi structured interviews. Political Science and Politics, 35(4), 665-668.

Loggen, R., Havenith, M., Spekschoor, J., Versendaal, J., \& Ravesteijn, P. (2011). Business process management in The Netherlands (In Dutch). Utrecht: Capgemini Nederland.

Luftman, J.N., Papp, R. \& Brier, T. (1999). Enablers and Inhibitors of Business-IT Alignment. Communications of the Association for Information System, Vol 1. Article 11.

Maes, R., Rijsenbrij, D., Truijens, O., \& Goedvolk, H. (2000). Redefining business-IT alignment through a unified framework. Amsterdam: Universiteit van Amsterdam. 
Mettler, T., \& Rohner, P. (2009). Situational maturity models as instrumental artifacts for organizational design. In: Proceedings of the 4th International Conference on Design Science Research in Information Systems and Technology, Philadelphia, PA.

Miles, M. B., \& Huberman, A. M. (1994). Qualitative data analysis (2nd ed.). Thousand Oaks: Sage.

Minahan, T. \& Degan, G. (2001). Best practices in e-procurement. Boston: Aberdeen group. The abridged report. Retrieved 2010-03-01 from http://www.hedgehog.com/resources/ e-ProcurementAbridged.pdf.

Monczka, R. M., Petersen, K. J., Handfield, R. B., \& Ragatz, G. L. (1998). Success factors in strategic supplier alliances: the buying company perspective. Decision Sciences, 29(3), 553-573.

Paulk, M. C., Curtis, B., Chrissis, M. B., \& Weber, C. V. (1993). Capability maturity model, version 1.1. IEEE Software, 10(4), $18-27$.

Plomp, M. \& Batenburg, R. (2009). Procurement maturity, alignment and performance: A Dutch hospital case comparison. Paper presented at the 22nd Bled eConference, Bled, Slovenia.

Pollice, F. \& Fleury, A. (2011). The link between purchasing and supply management maturity models and the financial performance of international firms. Retrieved 2011-11-03 from http:// www.ifm.eng.cam.ac.uk/cim/symposium2010/proceedings/3 pollice.pdf.

Pooley, R. (2007). Behavioral equivalence in simulation modeling. Simulation Modeling Practice and Theory, 15, 1-20.

Rankin, J. H., \& Luther, R. (2006). The innovation process: adoption of information and communication technology for the construction industry. Canadian Journal of Civil Engineering, 33(12), $1538-1546$.

Raschke, R.L. \& Ingraham, L.R. (2010). Business process maturity's effect on performance. Paper presented at the 16th Americas conference on information systems, Lima, Peru.

Rosemann, M. \& de Bruin, T. (2005). Towards a business process management maturity model. Paper presented at the 13th European conference on information systems, Regensburg, Germany.

Rozemeijer, F. (2000). How to manage corporate purchasing synergy in a decentralized company? Towards design rules for managing and organizing purchasing synergy in decentralized companies.
European Journal of Purchasing \& Supply Management, 6(1), 512.

Scheper, W. (2002). Business IT alignment: Solution for the productivity paradox (In Dutch). Utrecht: Deloitte \& Touche.

Schiele, H. (2007). Supply-management maturity, cost savings and purchasing absorptive capacity: testing the procurementperformance link. Journal of Purchasing and Supply Management, 13(4), 274-293.

Stalenhoef, K., Goedhart, E., van de Kamp, H., \& van der Heijden, G. (2007). World-class purchasing. Utrecht: Berenschot.

Thiry, M., \& Deguire, M. (2007). Recent developments in projectbased organizations. International Journal of Project Management, 25(7), 649-658.

Treacy, M., \& Wiersema, F. (1996). Discipline of market leaders: Choose your customer, narrow your focus, dominate your market. London: Harper-Collins.

Turban, E., McLean, E., \& Wetherbe, J. (1999). Information technology for management: making connections for strategic advantage. Chichester: Wiley.

Versendaal, J., \& Brinkkemper, S. (2003). Benefits and success factors of buyer-owned electronic trading exchanges: procurement at Komatsu America Corporation. Journal of Information Technology Cases and Applications, 5(4), 39-52.

van Weele, A. J. (2005). Purchasing and supply chain management: Analysis, strategy, planning and practice. London: Thomson International.

Weele, A. J. van, Rozemeijer, F.A. \& Rietveld, G. (2000). Professional development of purchasing in organizations: Towards a purchasing development model. Global purchasing \& supply chain strategies. Retrieved 2011-10-03, from http://www.touchbriefings. $\mathrm{com} / \mathrm{cdps} / \mathrm{cditem} . \mathrm{cfm} ? \mathrm{nid}=977 \& \mathrm{cid}=9$.

van de Wijngaert, L., Versendaal, J., \& Matla, R. (2008). Business IT alignment and technology adoption; the case of RFID in the logistics domain. Journal of Theoretical and Applied Electronic Commerce Research, 3(1), 71-80.

Yin, R. K. (2003). Case study research: Design and methods (3rd ed.). Thousand Oaks: Sage.

Yitmen, I. (2007). The challenge of change for innovation in construction: a North Cyprus perspective. Building and Environment, 42(3), 1319-1328. 